\title{
Impact of temperature on UV-susceptibility of two Ulva (Chlorophyta) species from Antarctic and Subantarctic regions
}

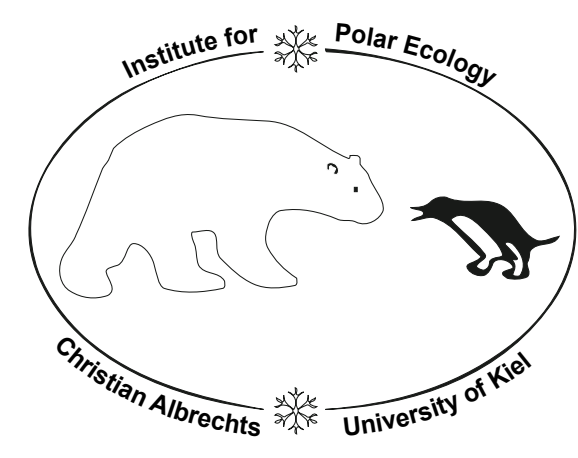

Ralf Rautenberger Institute for Polar Ecology Christian Albrechts University of Kiel (Germany) 


\section{The „Antarctic ozone hole“}

Total ozone (DU) / Ozone total (UD), 2005/10/08

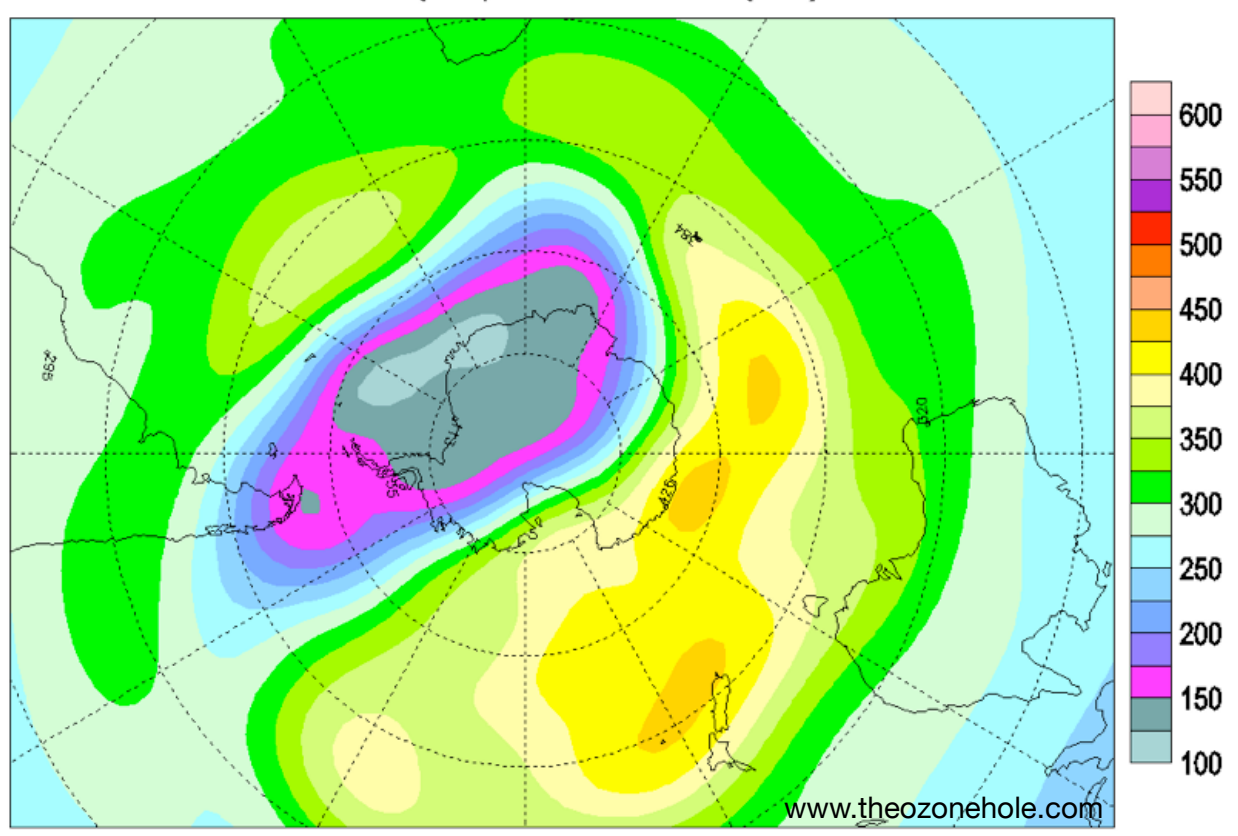

- $\quad$ Establishment in austral spring every year

- In 2000 and 2003: $\geq 28$ million $\mathrm{km}^{2}$

- Extended to South America: $45^{\circ} \mathrm{S}$

- Results in an increase of UV-Bradiation on earth's surface

- Increased UVB-radiation affects macroalgae as an important ecological component 


\section{Water temperatures}

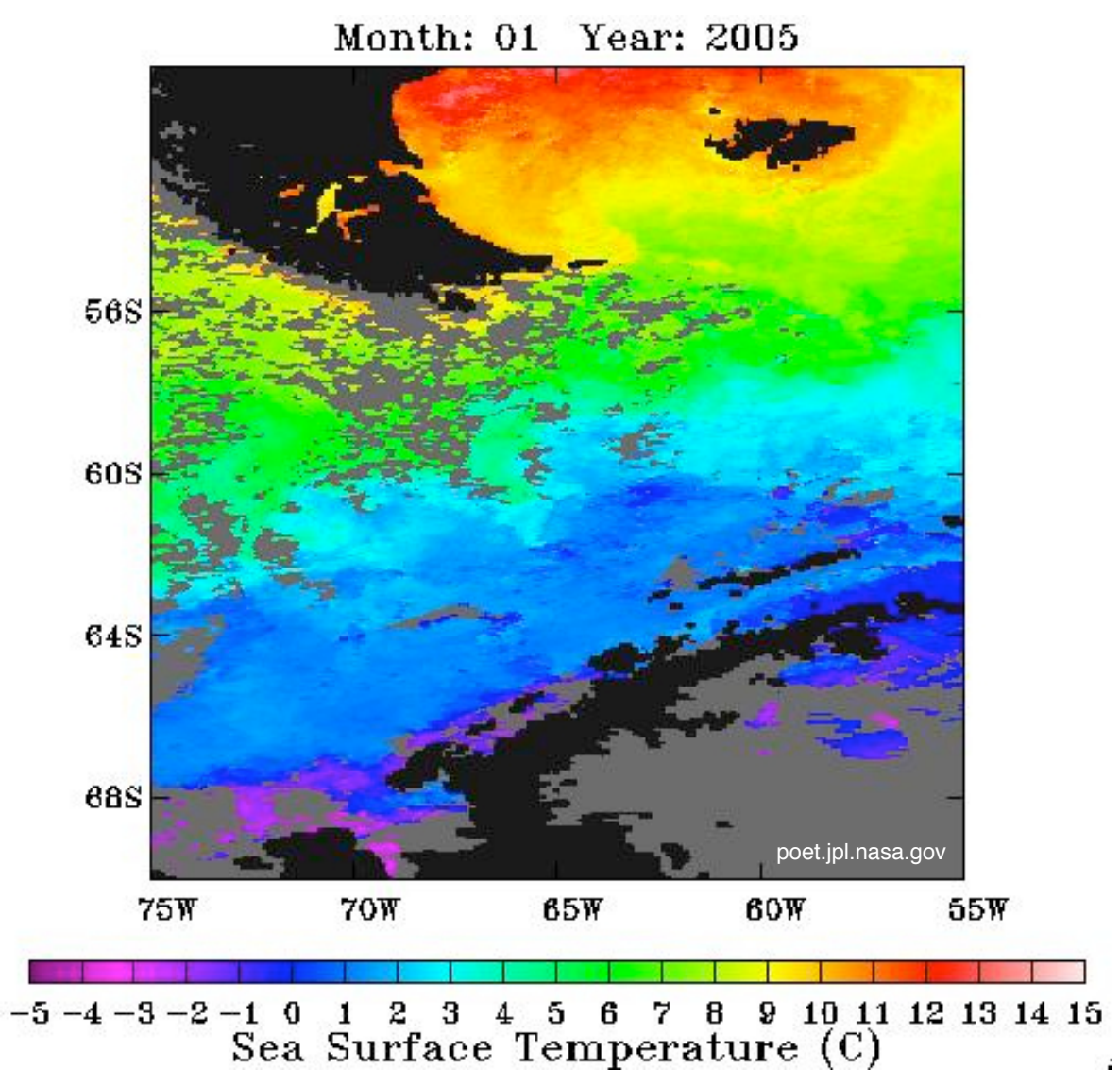

- Controlling macroalgal growth, distribution and stress

- Potential changes of water temperatures in Antarctica affect marine life, e.g. macroalgae 


\section{Algal material}

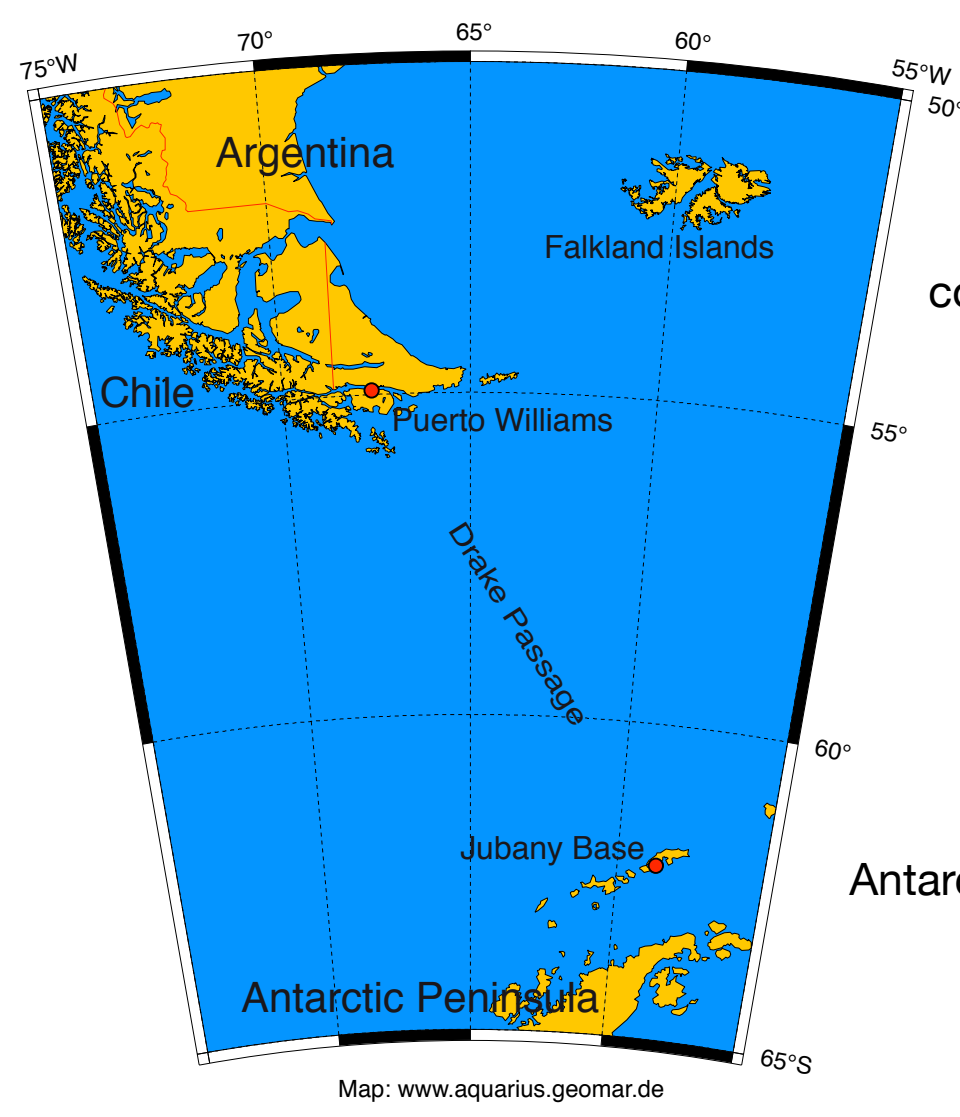

Puerto Williams:

Ulva clathrata

cosmopolitan/cold-temperate species cold-temperate waters: $5-10{ }^{\circ} \mathrm{C}$

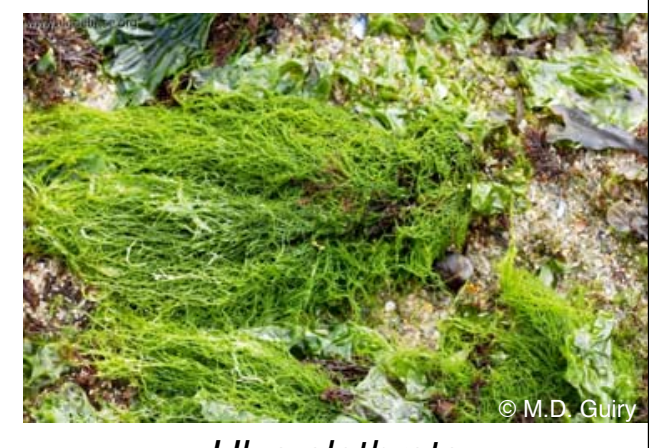

Ulva clathrata

Jubany Base:

Ulva bulbosa

Antarctic/cold-temperate species: $-2-2{ }^{\circ} \mathrm{C}$

Tide pools: $>>2{ }^{\circ} \mathrm{C}$

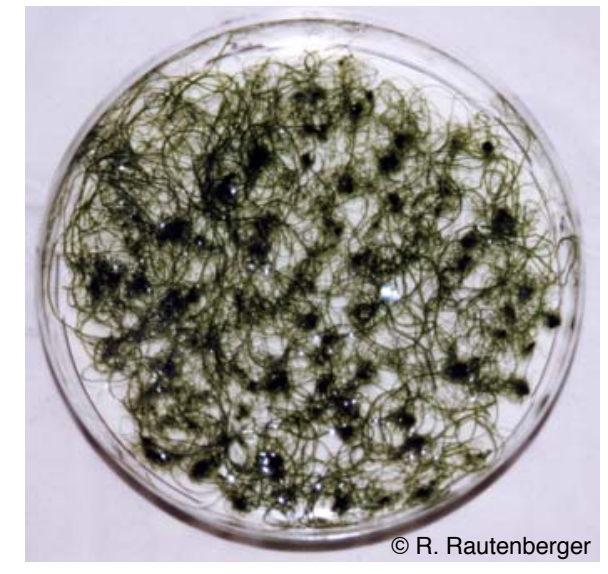

Ulva bulbosa 


\section{Objective of the study}

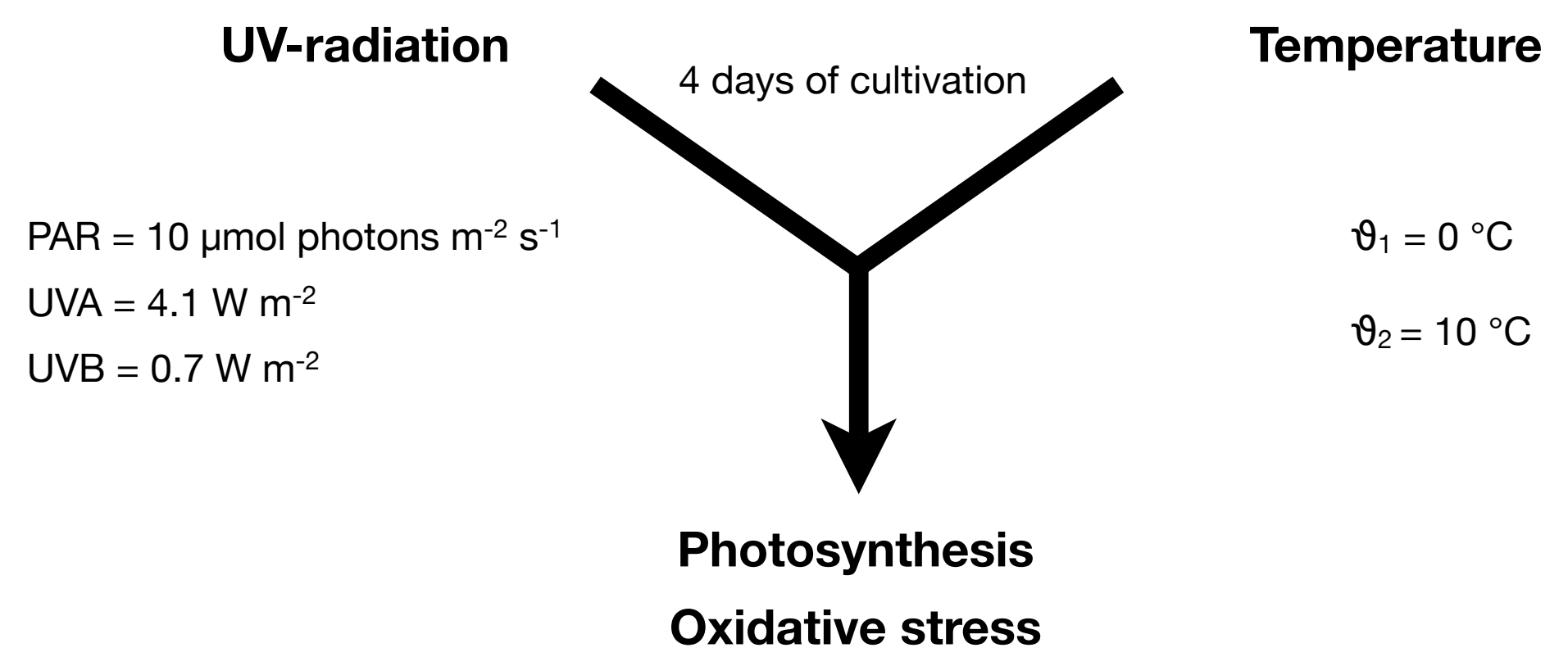

Interactive effects of UV-radiation and temperature on the physiological and ecological level 


\section{Photosynthesis of U. bulbosa}

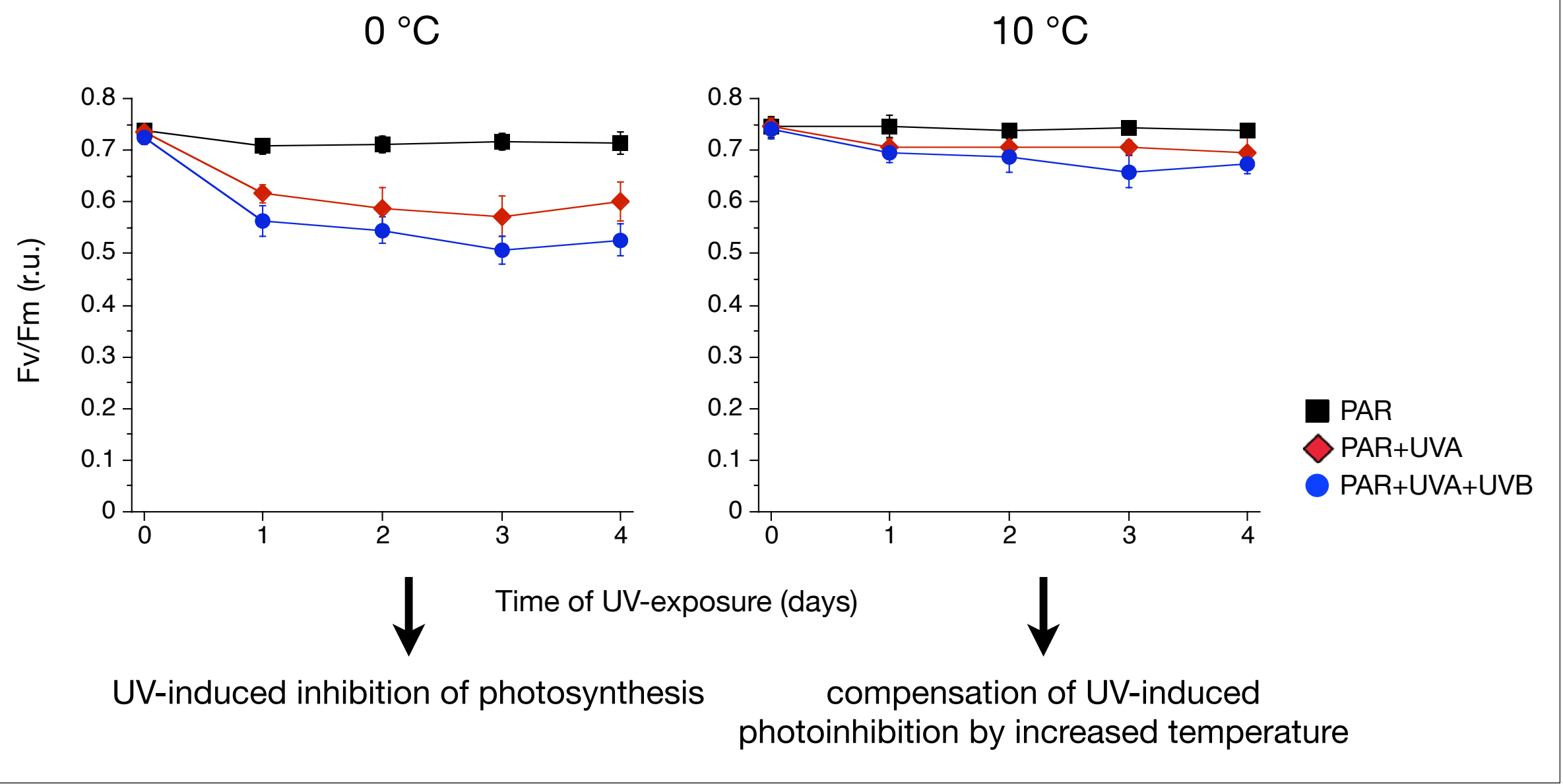




\section{Photosynthesis of $U$. clathrata}

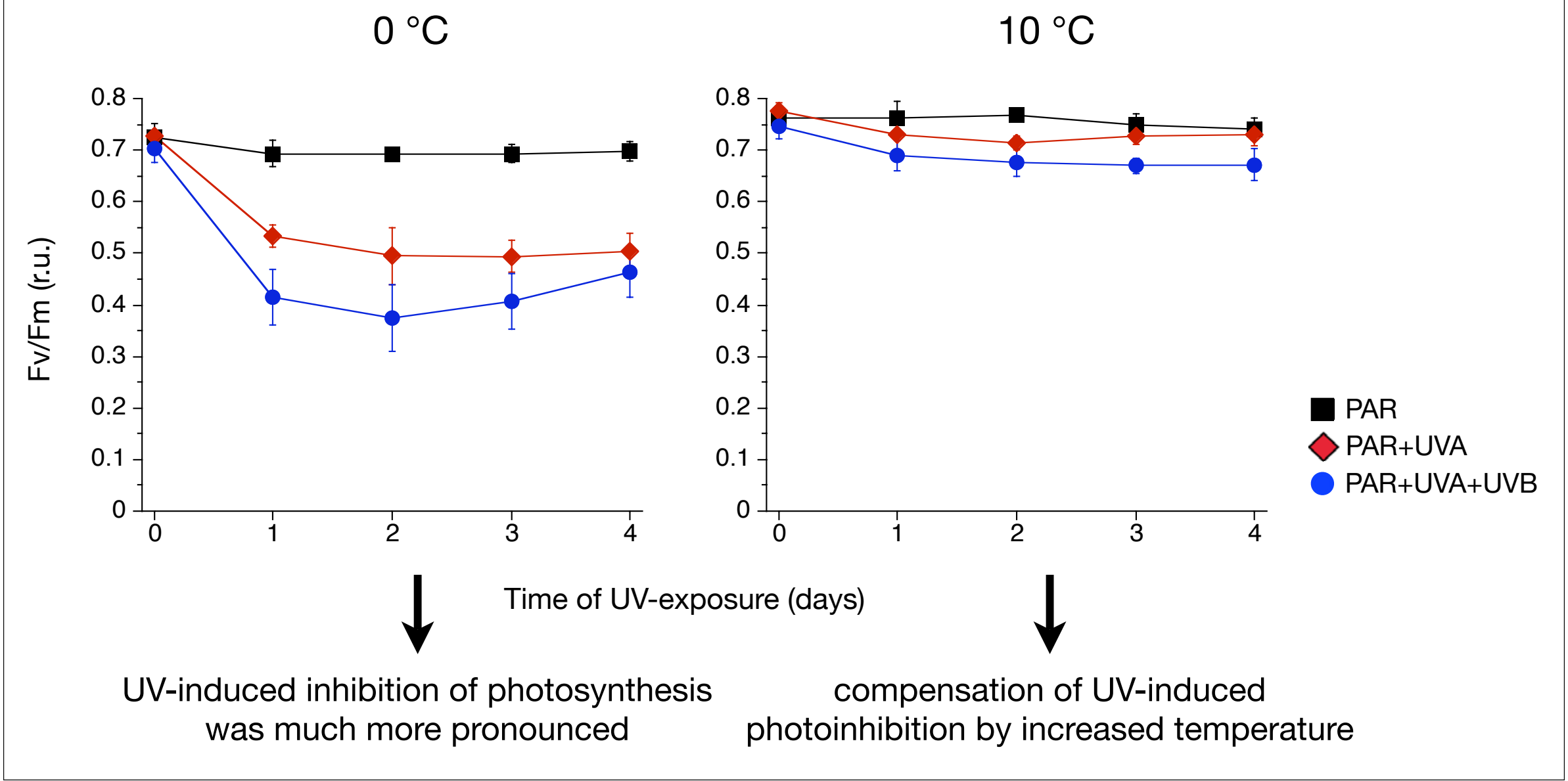




\section{Activities of superoxide dismutase in U.bulbosa}

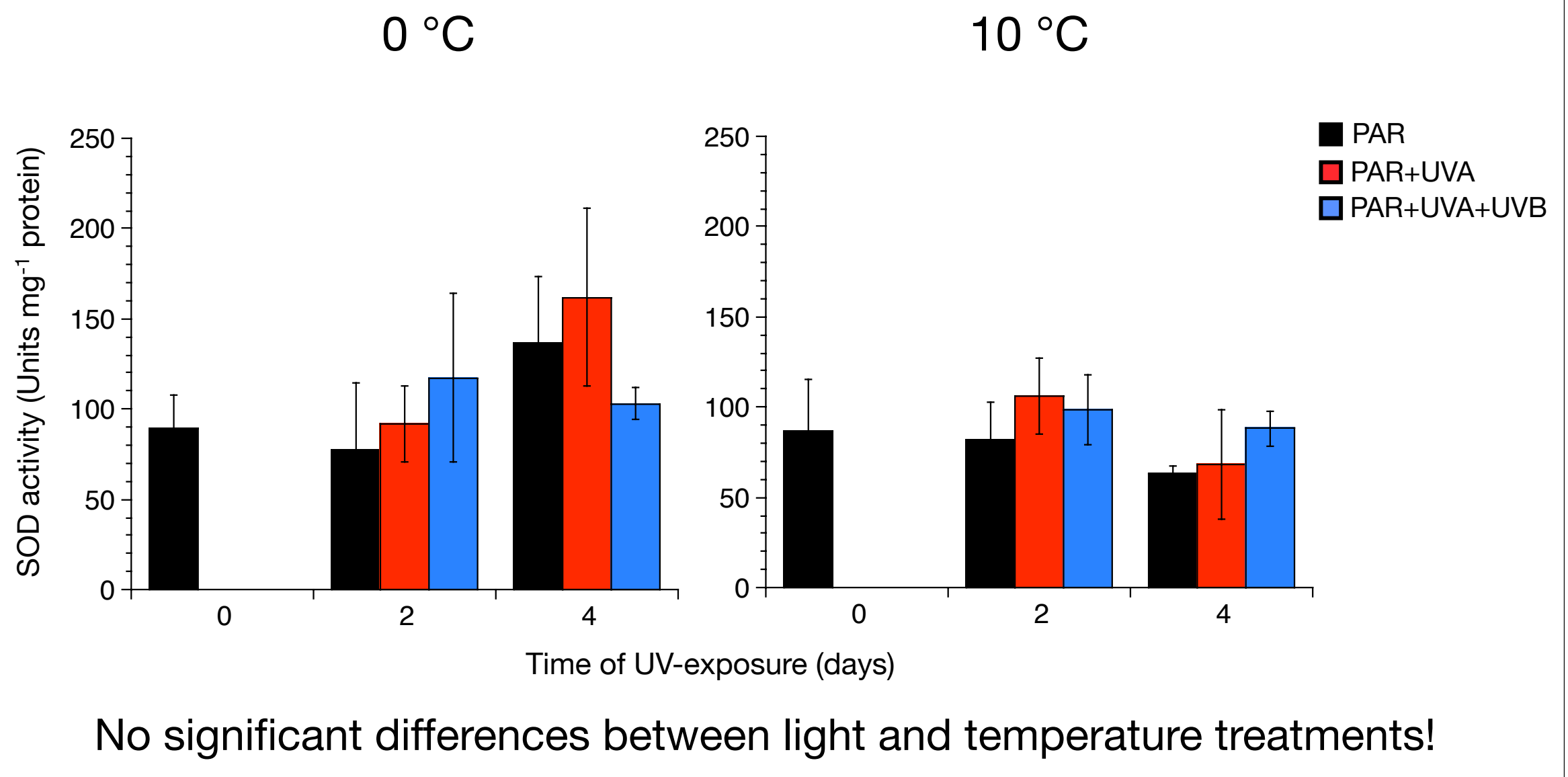




\section{Activities of superoxide dismutase in U.clathrata}

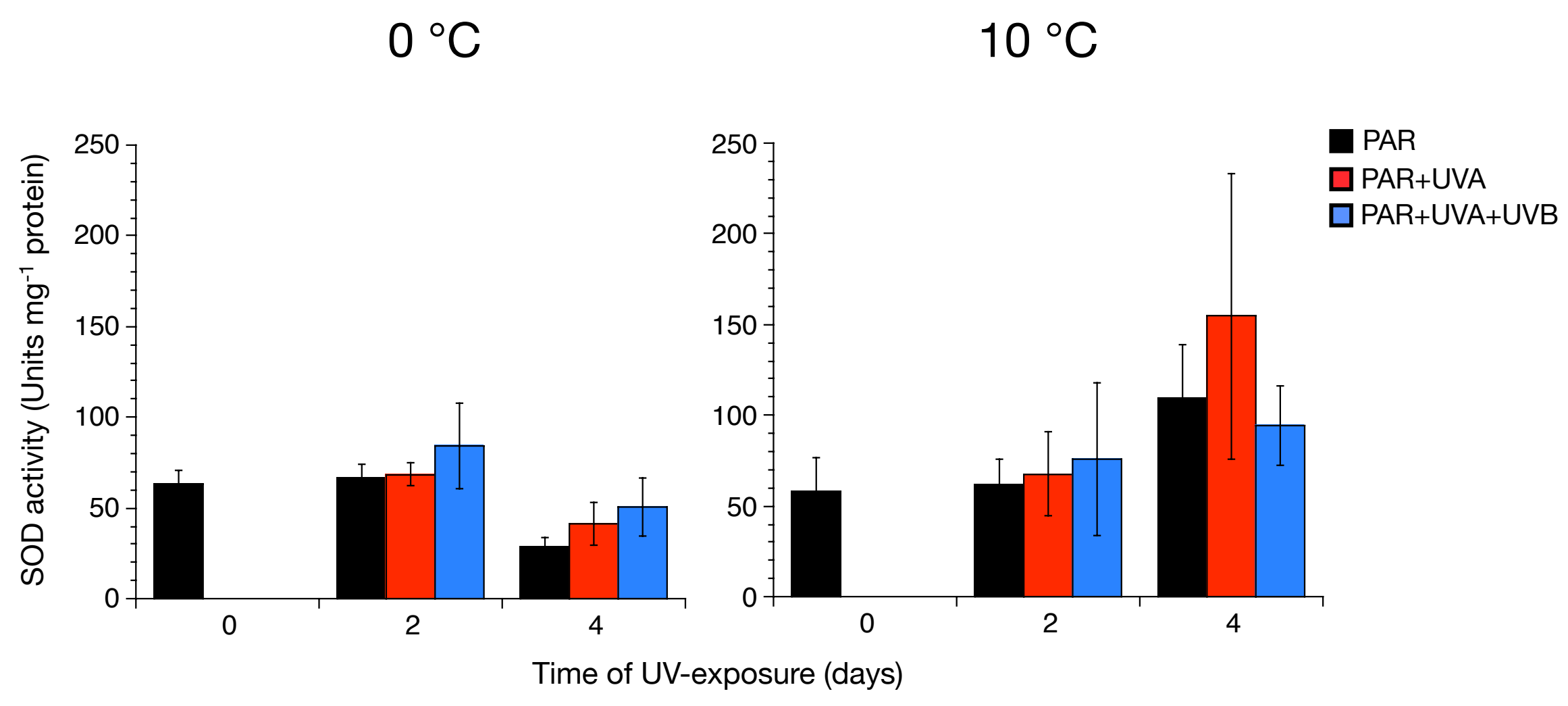

No significant differences between light treatments! 


\section{Content of malondialdehyde in U.bulbosa}

$0{ }^{\circ} \mathrm{C} \quad 10^{\circ} \mathrm{C}$

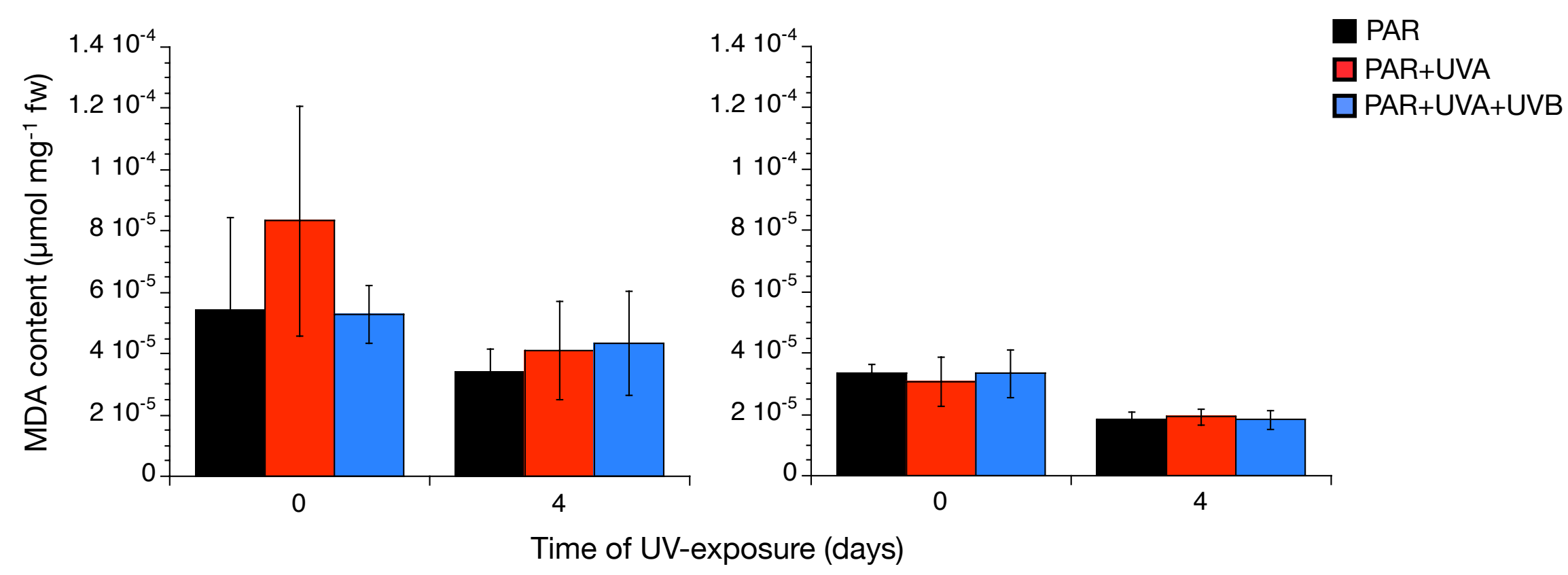

No significant differences between light treatments! 


\section{Content of malondialdehyde in U. clathrata}
$0{ }^{\circ} \mathrm{C}$
$10^{\circ} \mathrm{C}$

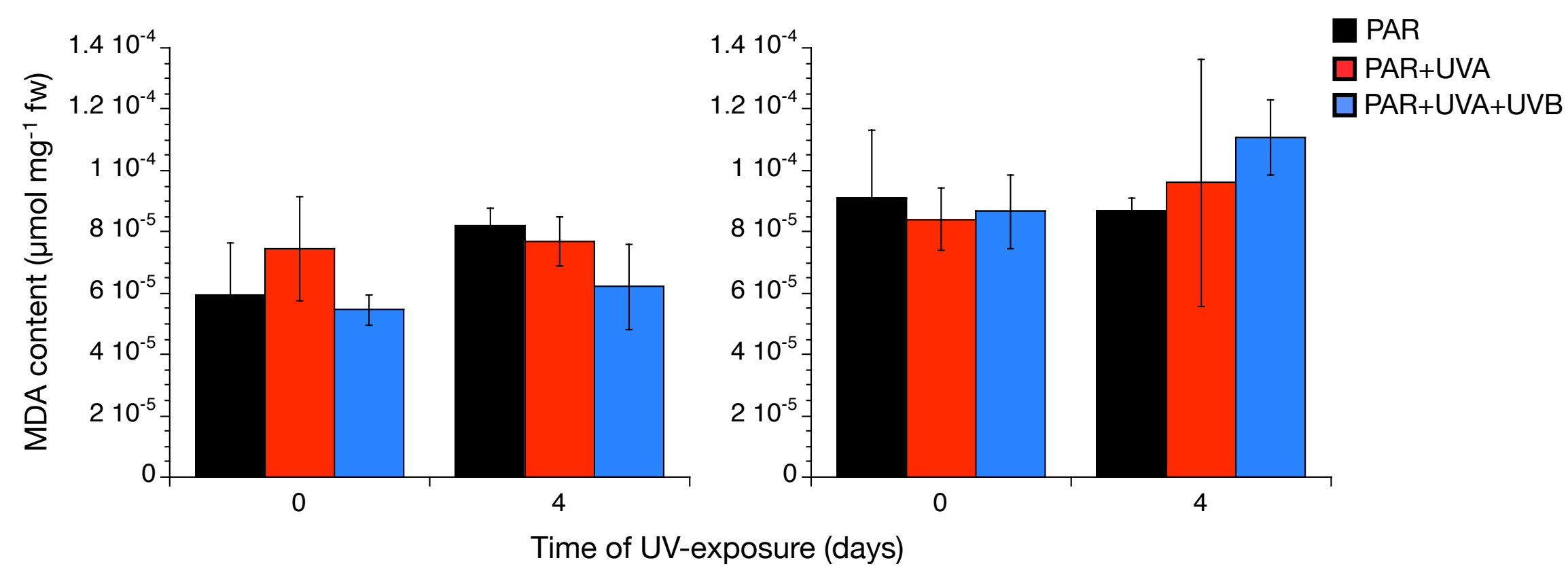

No significant differences between light treatments! 


\section{Physiological interpretation}

- UV-radiation induced inhibition of photosynthesis at $0{ }^{\circ} \mathrm{C}$ but did not cause any oxidative stress

- Compensation of UV-induced photoinhibition by increased temperature, probably due to increased activities of key enzymes involved in photoprotection

- Higher SOD activities in U. bulbosa than in U. clathrata suggest a more efficient management of oxidative stress at permanent low temperatures 


\section{Ecological Interpretation}

- U. bulbosa seems better adapted to cope with UVradiation than $U$. clathrata at lower temperatures

- U. bulbosa in the eulittoral is affected by UV-radiation but photoinhibition is reversible

- In tide pools, increased temperatures may diminish UVeffects in U. bulbosa

- U. clathrata from South America does not experience similarly low temperatures

- There, higher water temperatures facilitate a higher activity of physiological protection mechanisms

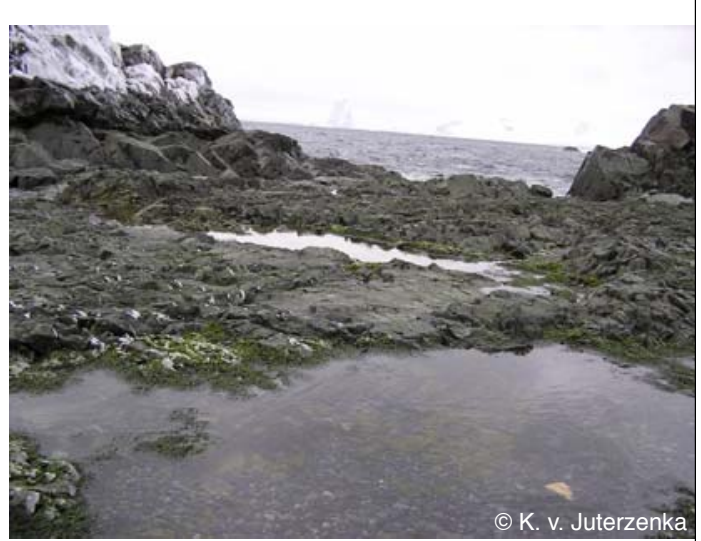




\section{Thank you for your attention.}

Deutsche

Forschungsgemeinschaft

DFG

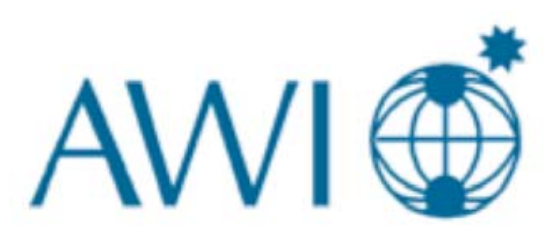

\section{$\mathbf{C}|\mathbf{A}| \mathbf{U}$}

Christian-Albrechts-Universität zu Kiel

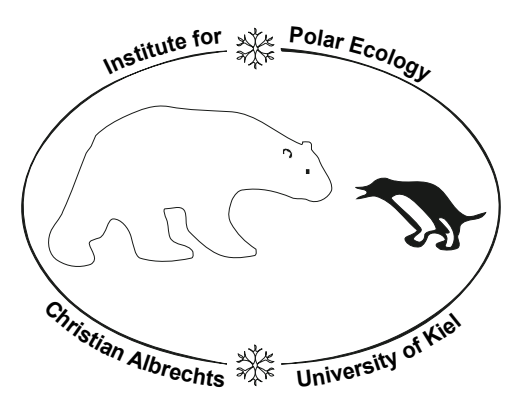

Rautenberger R and Bischof K (2006) Impact of temperature on UV-susceptibility of two Ulva (Chlorophyta) species from Antarctic and Subantarctic regions. Polar Biology (Online First) 